\title{
A Recommendation System Regarding Meeting Places for Groups during Events
}

\author{
Shota Asukai ${ }^{1}$ and Kayoko Yamamoto ${ }^{2, *}$ \\ 1 Department of Informatics and Engineering, University of Electro-Communications, Chofu 182-8585, Japan; \\ arsenic.0407@gmail.com \\ 2 Graduate School of Informatics and Engineering, University of Electro-Communications, \\ Chofu 182-8585, Japan \\ * Correspondence: k-yamamoto@is.uec.ac.jp; Tel.: +81-42-443-5728
}

Received: 13 June 2018; Accepted: 19 July 2018; Published: 25 July 2018

\begin{abstract}
The present study aimed to design, develop, operate, and evaluate a recommendation system for meeting places targeting groups of two or more people during events. The system was designed and developed by integrating an accessibility database, as well as a recommendation system, and linking with Google Maps and social networking services (SNSs, Twitter and LINE). Additionally, the system was operated for 5 weeks with people mainly in the Tokyo metropolitan area, with Japan as the target, and the total number of users was 59. Based on the results of the web questionnaire survey, it was made evident that the system is useful for groups when meeting up, and the entry function for the nearest station to one's home, as well as the recommendation function for meet-up stations, which was the original functions of the system, received generally good reviews. From the results of access analysis of the users' log data, it was made evident that the system was used regardless of the type of device, just as the system was designed for, and that the system was used in harmony with the aim of the present study, which is to recommend meet-up stations for groups.
\end{abstract}

Keywords: recommendation system; accessibility database; social networking service (SNS); Google Maps; meeting place; railway station

\section{Introduction}

In Japan, and especially in the urban areas, various kinds of events, such as musical and dramatic entertainment, are frequently held. Overcrowding around venue areas is always a serious issue when such events are held. Because many of these events sell tickets in pairs, it is common for two people to attend the event together, and it is necessary for those attending to meet up and exchange tickets before the event. Additionally, there are cases where several pairs gather and make up a medium-sized group, and such groups also try to gather around the event venue before and after the event. It takes a great amount of time for such groups to meet up before and after the event in such a crowded area, and as they do not move right away from the area after meeting up, the congestion around the event venue can last for a long time. While large-scale events may have exit control, this is not effective due to the overcrowding caused by the abovementioned groups trying to meet up.

Therefore, it is necessary to reduce the congestion and control the movements of those attending events in order to do so. By guiding them to a designated location away from the event venue, the congestion of meeting places for groups may be reduced. However, such meeting places must be easily accessible for each individual within the group. Additionally, as a condition for deciding on a meeting place for groups, there must be an adequate number of facilities in the area. Based on these conditions, limiting meeting places to a station (excluding the nearest station to the event venue) 
on the train line on which the nearest station to the event venue is located, the present study aims to design, develop, operate, and evaluate a recommendation system for meeting places targeting groups of two or more people. The system will focus on accessibility, which will be defined as the accessibility between two arbitrary stations accurately reflecting the actual usage situation.

\section{Related Work}

The present study is related to three study fields, including (1) studies related to travel support systems and methods, (2) studies related to recommendation systems and methods of locations, and (3) studies related to the accessibility between two points. In the first category of studies-studies related to travel support systems and methods-Ishizuka et al. (2007) [1] proposed a similarity search method for the movement locus of tourists from the location information, as well as the related text information. Kurashima et al. (2011) [2] proposed a travel route recommendation method using the geotags of photo-sharing sites. Kurata (2012) [3] developed an automatic sightseeing route system using geographic information systems (Web-GIS) and genetic algorithms (GAs). Sasaki et al. (2013) [4] gathered information concerning regional resources and developed a system that offers travel support for each user. Fujitsuka et al. (2014) [5] used the pattern-mining method, which lists and extracts the chronological movement of those visiting sightseeing spots to develop an outing plan recommendation system. Ueda et al. (2015) [6] generated posterior information from the movement of users while sightseeing and developed a sightseeing support system, which shares such information as prior information with other users. In order to support sightseeing activities under normal circumstances, as well as an evacuation during a disaster, Fujita et al. (2016) [7] developed a navigation system using augmented reality (AR), Web-GIS, and social media. Mizushima et al. (2016) [8] proposed a sightseeing tour recommendation system using data related to traveler demands (location, time, and purpose). Just targeting foreigners visiting Japan, Yamamoto (2018) [9] developed a sightseeing navigation system using the two-dimensional and three-dimensional digital maps of Web-GIS with Fujita et al. (2016) [7] as a reference.

The second category of studies-studies related to recommendation systems and methods of locations-are important for the studies of location-based social networks (LBSN). Canneyt et al. (2011) [10] proposed a recommendation system for sightseeing spots. Batet el al. (2012) [11] developed a recommendation system for sightseeing spots using a multi-agent system. Uehara et al. (2012) [12] extracted sightseeing information from the web, calculated the similarities between sightseeing spots using several feature vectors, and developed a recommendation system for sightseeing spots. Shaw et al. (2012) [13] took into consideration the location information and travel records of users and developed a system that presents users with a list of sightseeing spots located in the vicinity. Ikeda et al. (2014) [14] integrated Web-GIS, social networking services (SNSs), and a recommendation system, accumulated sightseeing spot information, and developed a social recommendation GIS to recommend sightseeing spot information according to the preferences of each user. Okuzono et al. (2015) [15] considered the preferences of several people using photos and proposed a recommendation system for sightseeing spots. Zhou et al. (2016) [16] developed a sightseeing spot recommendation system using AR, Web-GIS, and SNSs.

Additionally, Mizutani et al. (2016) [17] referred to Ikeda et al. (2014) [14] and Okuzono et al. (2015) [15] and developed a social recommendation GIS that considered the change in situation of several users. Xu et al. (2017) [18] proposed a location recommendation system using the GPS locus of users, while Abe et al. (2017) [19] developed a tourism information system with language-barrier-free interfaces, mainly targeting foreign visitors.

In the third category of studies-studies related to the accessibility between two points-Zhang et al. (2000) [20] focused on the accessibility between two stations and evaluated the serviceability of railway lines in Japan and Korea. Additionally, there are systems that deal with accessibility besides those presented in research papers. For example, "Atsumaru-now" [21] is a web system where 
users can search for meet-up stations from several departure stations. Moreover, Navitime [22] and Yahoo! [23] offer a web service to search for routes between two locations.

The first and second categories of studies mentioned above do not take into consideration the use of trains. Additionally, excluding Okuzono et al. (2015) [15] and Mizutani et al. (2016) [17], the preceding second category of studies only include individuals as recommendation targets and do not consider groups. Furthermore, though Okuzono et al. (2015) [15] includes groups as recommendation targets, because user profiling is conducted by categorizing preference information using photos, there is a possibility that sightseeing spots that do not match the user's preferences will be displayed. Moreover, Mizutani et al. (2016) [17] only recommends sightseeing spots for groups and does not recommend meet-up locations prior to that. Regarding the existing system of the third category of studies, while a search can be conducted for meet-up stations focusing on time, distance, and the number of transfers, as only one item can be focused on, meet-ups before getting to the destination are not considered. Therefore, the present study intends to improve the accessibility calculation method proposed by Zhang et al. (2000) [20] and demonstrate originality by recommending convenient meeting places for groups during events.

\section{System Design}

\subsection{System Characteristics}

As shown in Figure 1, the system in the present study is composed based on the accessibility database, and the recommendation system is linked with Google Maps, as well as external SNSs (Twitter and LINE). The purpose of the system is to reduce congestion around event venues by recommending meet-up stations before and after the event for groups, as well as to recommend stations that are easily accessible for everyone within a group, based on the nearest station to the home of each individual within the group and the accessibility value calculated beforehand. On the page for the recommendation function for the meet-up stations, the top three stations with the highest accessibility values will be recommended. By displaying the total value of the travel time required and the number of transfers to the three stations for each individual within the group, users can make a final decision on the station at which to meet.

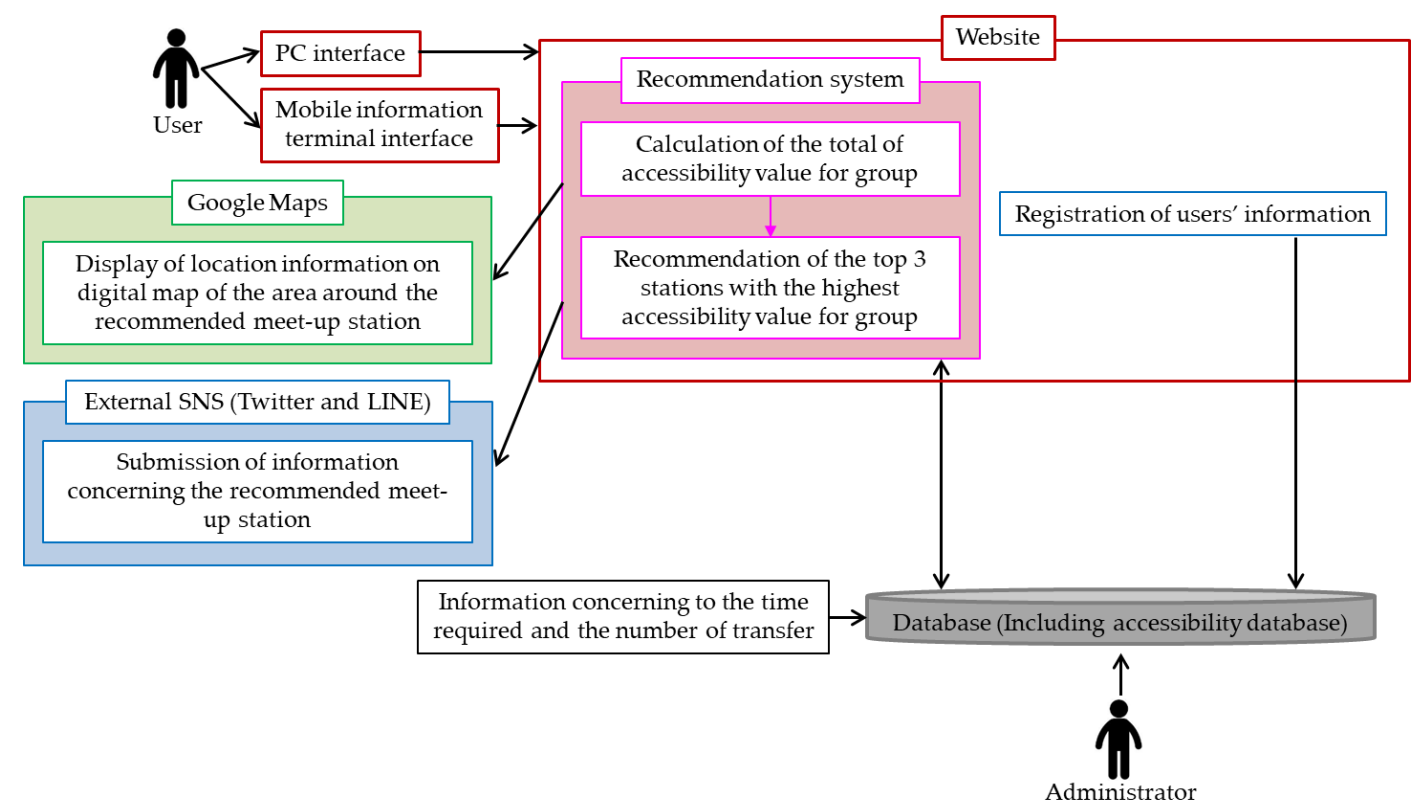

Figure 1. System design. SNS: social networking service. 
Further, by creating a link with Google Maps on the page for the recommendation function for the meet-up stations, the users can display digital maps, as well as search for any available facilities around the meet-up station and a route to the meet-up station from any point. Additionally, buttons linked with Twitter and LINE were installed on the page for the recommendation function for the meet-up stations, which enable the users to share information concerning the recommended meet-up stations within the group using their own account for the above SNSs. Accordingly, by recommending stations at which groups can easily meet up, the system encourages people to gather in places away from event venues. As mentioned in Section 1, groups try to gather around the event venue before and after the event, and overcrowding around venue areas is always a serious issue.

\subsection{Target Information Terminals}

Though the system is meant to be used from PCs (Personal Computers) or mobile devices, as there is no difference in functions on different information terminals, the same function can be used from any device. No matter what device is used, the system is intended to support the final decision of meet-up stations for groups both before and after an event.

\subsection{System Operation Environment}

The system operates using the web server and database server. Figure 2 shows the operating environment of the system. The web server and database server both use Heroku, which is a platform as a service (PaaS) provided by the Salesforce.com Co., Ltd. (San Francisco, CA, United States). The web application developed with the system was implemented using PHP (Hypertext Preprocessor) and JavaScript. For the development of the system, jQuery is used as the framework among JavaScript libraries.

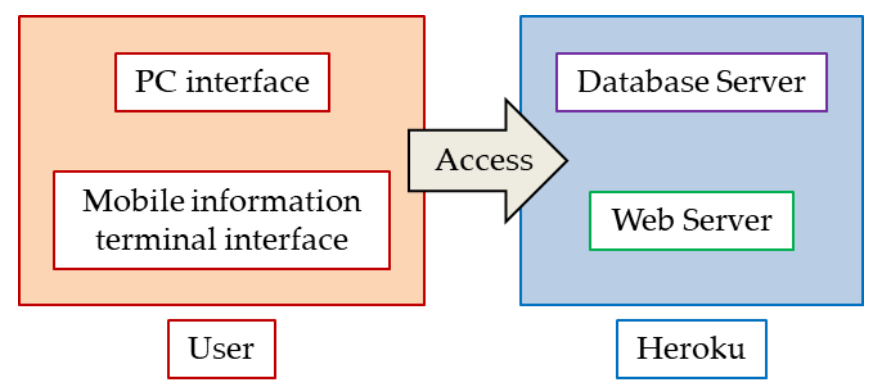

Figure 2. System operating environment.

\subsection{Details of the System Design}

In the system, the suggested meet-up stations will include all stations (excluding the nearest station to the event venue) on the same railway line on which the nearest station to the event venue is located. The reason for this is that the purpose of the system is the reduction of congestion near the event venue, and the nearest station as the meet-up station is unsuitable. Additionally, when considering the accessibility for before and after the event, it is best to have a meet-up station that can be accessed without transfer from the nearest station.

In order to recommend a meet-up station, it is necessary to obtain information regarding the nearest station to the home of each individual within the group. As the system will be used by general people, the entry method for such information is designed to be easy and reliable. Specifically, the users can first select the line to which their nearest station belongs from a list of railway lines and then select their nearest station from a list of stations on that train line. Then, the top three stations with the highest accessibility value between the nearest station to the home of each individual within the group and the suggested meet-up stations will be recommended as the meet-up stations. Based on the reason mentioned in the previous paragraph, the nearest station to the event venue will be excluded from the 
suggested meet-up stations by the constraint in the algorithm of the process of the recommendation system in the backend.

Figure 3 shows a specific example of a meet-up station recommended to a group consisting of three individuals. In this case, Station $X$ is easily accessible for $A$ and $B$ but is inconvenient for $C$. Either $C$ will have to use this inconvenient route or travel separately. In order to prevent such a situation, Station $Y$ with the highest accessibility value for all within the group will be recommended.

Moreover, in addition to the accessibility value used for the recommendations, the database is also developed with the travel time required, as well as the number of transfers. The reason for this is that the travel time required and the number of transfers to the three stations are displayed on the page for the recommendation function for the meet-up stations as reference indexes for the users when deciding upon a meet-up station after the three stations are recommended with the method mentioned above.

\begin{tabular}{|l|r|r|r|}
\hline Person & X & Y & Z \\
\hline A & 160 & 130 & 70 \\
\hline B & 80 & 70 & 60 \\
\hline C & 30 & 80 & 50 \\
\hline Total of accessibility value & 270 & 280 & 180 \\
\hline \multicolumn{4}{|c|}{} \\
\\
The system will recommend Station $Y$ \\
as a meeting-up station to the group.
\end{tabular}

Figure 3. Specific example where a station is recommended as a meeting place for a group of three people.

\section{Definition of Accessibility and Database Creation}

\subsection{Definition of Accessibility in Preceding Studies}

With the JR Tozai line (Osaka) and the subway line 5 (Seoul) as targets, Zhang et al. (2000) [20] calculated the accessibility values using Equation (1). Then, by calculating the accessibility value from an arbitrary station $i$ to another arbitrary station $j$ and its total value, the serviceability of the entire railway line is evaluated.

$$
N . A .=e^{-\alpha t_{i j}}\left(1-e^{-\beta X_{i j}}\right) N_{j}
$$

where N.A. is the accessibility value; $\alpha t_{i j}$ is the travel time required between stations $i j(\mathrm{~min}) ; X_{i j}$ is the maximum transportation capacity between stations $i j\left(10,000\right.$ people); $N_{j}$ is the average number of passengers getting on and off at the station $j$ (arrival station) per day; and $\alpha, \beta$ is the parameter $(\alpha, \beta>0)$.

As Zhang et al. (2000) [20] defines the accessibility with a single railway line as a target, the calculations end with factors from a single line. The travel time is the time required to go to another station, the maximum transportation capacity is the number of passengers that can be transported per unit time, and the average number of passengers getting on and off per day represents the scale of the arrival station.

\subsection{Definition of Accessibility in the Present Study}

In reality, when using railway lines to travel, there are many cases where the use of two or more railway lines are necessary. Therefore, the equations for the accessibility values of the preceding studies mentioned above are not fit for travel that include transfers, and the factors of the maximum transportation capacity are not directly connected to the accessibility between two stations. Therefore, in the present study, by converting the factors from the maximum transportation capacity to the number of transfers required to the destination, there will be an index that shows the travel accessibility when using several railway lines. However, in contrast with the factors of the maximum transportation capacity, which is better high, because the factors of the number of transfers are better low, it is essential 
to modify a part of Equation (1). The equation of the accessibility values used in the present study is as shown in Equation (2). In this way, the bases for calculating the accessibility values in the present study are the travel time required and the number of transfers to the arrival station, as well as the average number of passengers getting on and off at the arrival station per day. Furthermore, in the present study, the arrival station is also the meet-up station for groups.

$$
\text { A.C. }=e^{-\alpha \mathrm{t}_{i j}} e^{-\beta X_{i j}} N_{j}
$$

where A.C. is the accessibility value; $\alpha t_{i j}$ is the travel time required between stations $i j(\mathrm{~min}) ; X_{i j}$ is the number of transfers required between stations $i j$ (times); $N_{j}$ is the average number of passengers getting on and off at the station $j$ (arrival station) per day; and $\alpha, \beta$ is the parameter $(\alpha, \beta>0)$.

\subsection{Accessibility Calculations and Database Creation}

Table 1 introduces the sources of the data used to calculate the accessibility values. Regarding the data, which used the search results obtained from Yahoo!Norikae, web scraping was conducted after deciding on an operation target area in order to accurately reflect the current usage situation. In the same way, for the data of the average number of passengers getting on and off at the station per day, the figures from all train stations within the operation target area were extracted. In the database of the system, data concerning the accessibility value, travel time, and the number of transfers for all train stations within the operation target area were inserted and are able to be accessed from the recommendation system.

Table 1. Sources of the data used to calculate the accessibility values.

\begin{tabular}{ll}
\hline Travel time & Yahoo!JAPAN, Transit [23] \\
\hline Number of transfers & Yahoo!JAPAN, Transit [23] \\
\hline $\begin{array}{l}\text { Average number of passengers getting on and } \\
\text { off at the station per day }\end{array}$ & $\begin{array}{l}\text { Digital national land information (2015) provided by the } \\
\text { Ministry of Land, Infrastructure, Transport, and Tourism [24] }\end{array}$ \\
\hline Data concerning station and railway line & Station data provided by the Station Data.jp [25] \\
\hline
\end{tabular}

\section{System Development}

\subsection{The Frontend of the System}

The system will implement unique functions for the users, which will be mentioned below, in response to the aim of the present study, as mentioned in Section 1. In order to implement these two unique functions, the system was developed by integrating plural systems into a single system and is also connected with Google Maps and SNSs.

\section{(1) Entry Function for the Nearest Station to Home}

Figure 4 shows the page for the entry function for the nearest station to home. After logging in to the system, by clicking on "Use system" at the top of the screen, the users can go to the page for the entry function for the nearest station to home. The users can create and assign their groups and enter the nearest stations to their homes by themselves on this page. As for the latter, they can select their railway lines and stations. 


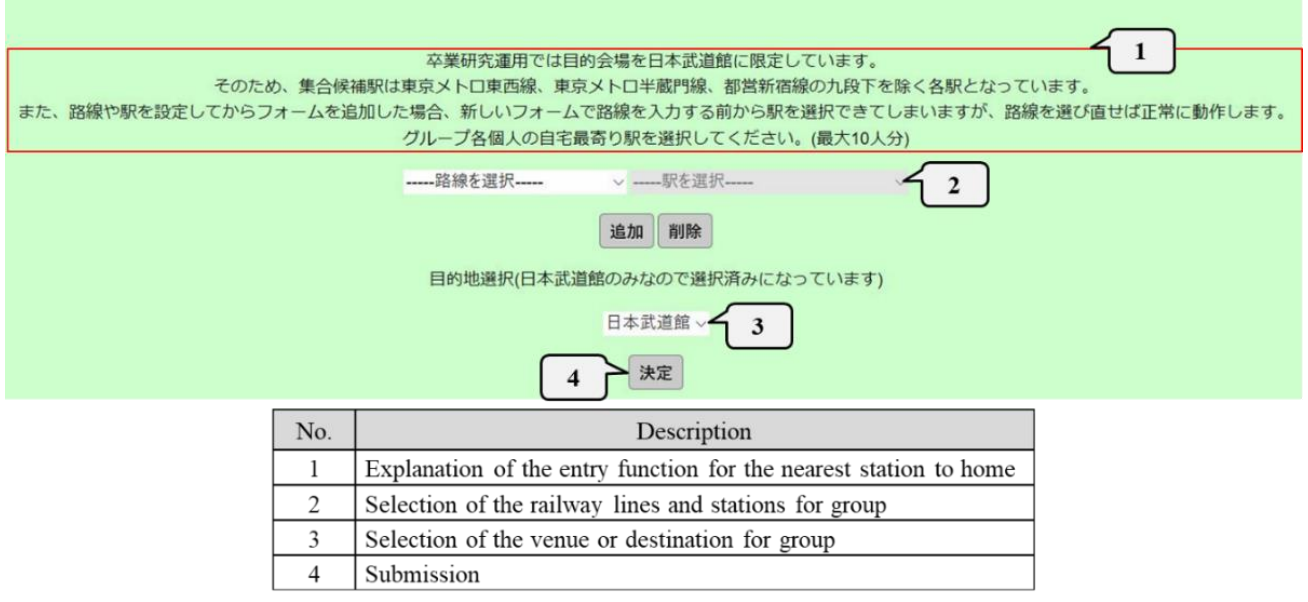

Figure 4. Page for the entry function for the nearest station to home.

\section{(2) Recommendation Function for Meet-Up Stations}

Figure 5 shows the page for the recommendation function for the meet-up stations. After entering and sending all the information on the page for the entry function for the nearest station to home, the users will be automatically directed to the page for the recommendation function for the meet-up stations. On this page, three recommended meet-up stations are displayed in order according to the greatness of the accessibility value of all those within the group, without any consideration for the total value of the travel time required and the number of transfers to the three stations for each individual within the group. By clicking the recommended stations, the users will be directed to a digital map of the area around that station on Google Maps. On the page for Google Maps, the users can display digital maps, as well as search for any available facilities around the meet-up station and a route from an arbitrary point to the meet-up station. Additionally, the users will be directed to their accounts of Twitter and LINE by clicking the button for "Tweet" or "Send through LINE" on the bottom of the screen, where they can share information concerning the recommended meet-up station within their group.

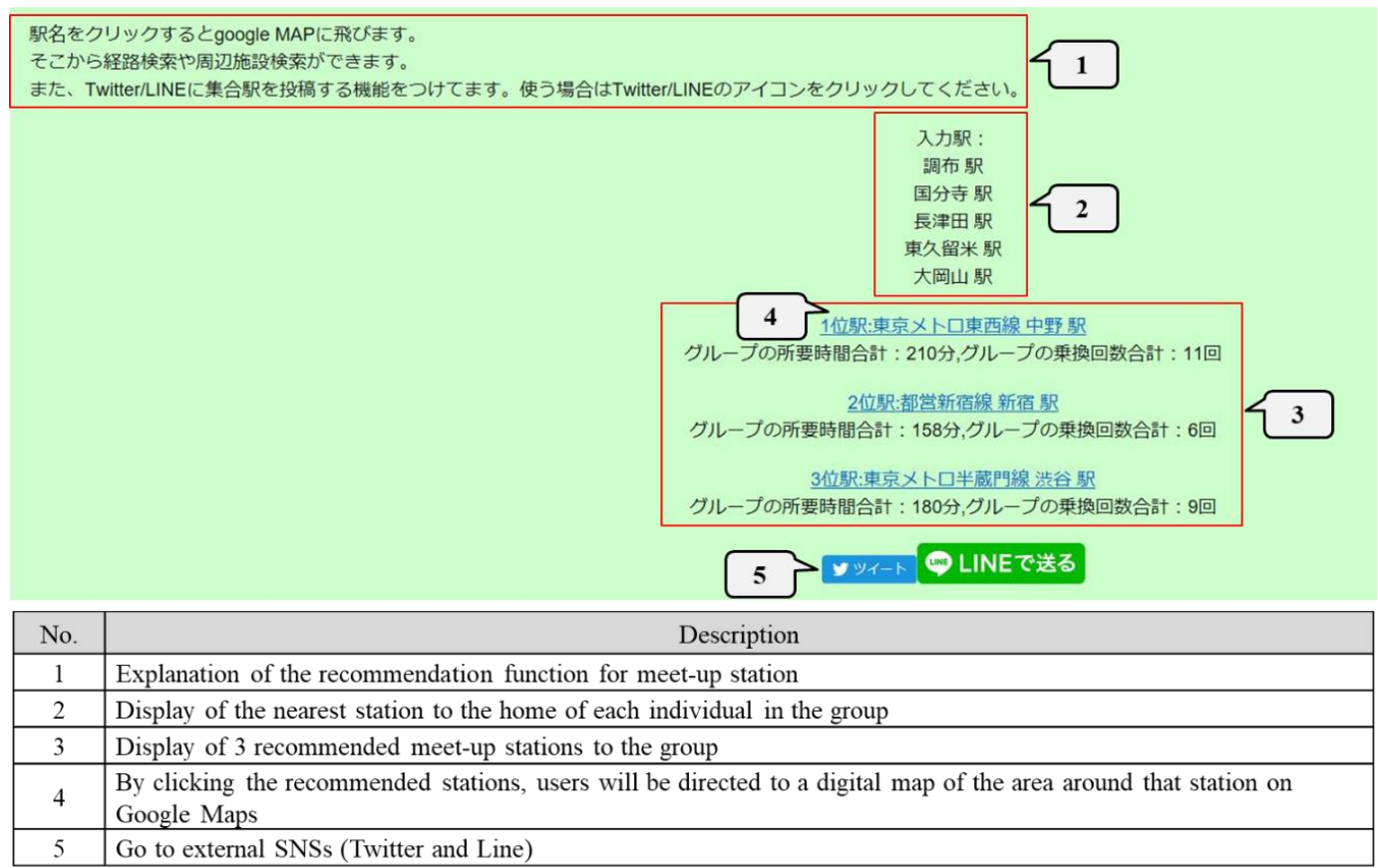

Figure 5. Page for the recommendation function for the meet-up stations. 
The processes of the links with Google Maps and the sharing system of the information concerning the meet-up station linked with external SNSs in the backend will be clearly explained in Section 5.2. Additionally, the links with Google Maps and external SNSs are just displayed on this page. Referring to the information concerning the travel time required and the number of transfers to the above three recommended meet-up stations on this page, in addition to the digital maps on the page for Google Maps, the users can ultimately decide their meet-up station by themselves through discussion within their group.

\subsection{The Backend of the System}

\section{(1) Process of the Recommendation System}

Figure 6 shows the conceptual diagram related to the process of the recommendation system. The calculation process of the accessibility value of all those within the group will be conducted in the background. This process enables the user groups to receive recommendations by entering the nearest stations to their homes, as well as to the event venue or destination. The total accessibility value for each suggested meet-up station will be calculated by obtaining the accessibility value between the nearest station to each individual's home as described in Section 4.2, which is entered by the user, and the suggested meet-up stations from the database created in Section 4.3. Only the top three stations with the highest accessibility value will be displayed along with the obtained information concerning travel time and the number of transfers.

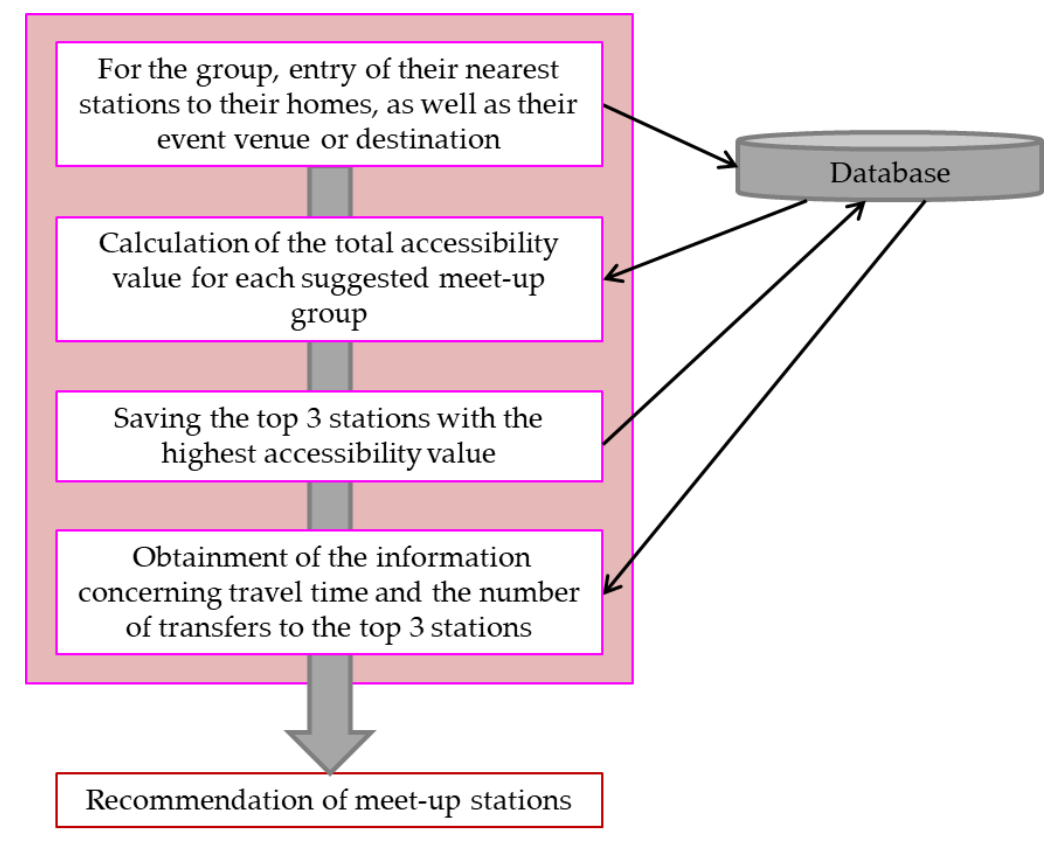

Figure 6. Conceptual diagram related to the process of the recommendation system.

\section{(2) Process of the Links with Google Maps}

Figure 7 shows the conceptual diagram related to the process of the links with Google Maps. Regarding the link with Google Maps, after selecting the top three stations with the highest accessibility value within the recommendation system, a link set with a search word parameter of Google Maps will be created. It was implemented by embedding a link generated in the station names when the meet-up stations are displayed on the page for the recommendation function for the meet-up stations. 


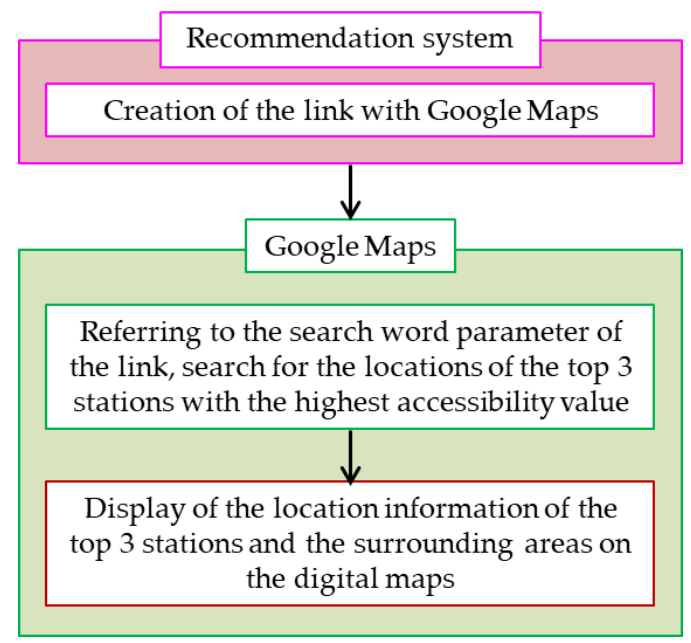

Figure 7. Conceptual diagram related to the process of the links with Google Maps.

(3) Process of the Sharing System of the Information Concerning the Meet-Up Station Linked with External SNSs

Figure 8 shows the conceptual diagram related to the process of the sharing system of the information concerning the meet-up station linked with external SNSs. Links with external SNSs (Twitter and LINE) were implemented in the recommendation function for the meet-up stations, using the library of Twitter OAuth, which was created for developers for Twitter, and the library of "Send through LINE" of LINE Social Plugins for LINE. The system was designed so that there is no need to register login information for Twitter or LINE. The system automatically enters fixed information when the application software (app) of Twitter or LINE is activated by clicking the button "Tweet" or "Send through LINE" on the page for the recommendation function for the meet-up stations.

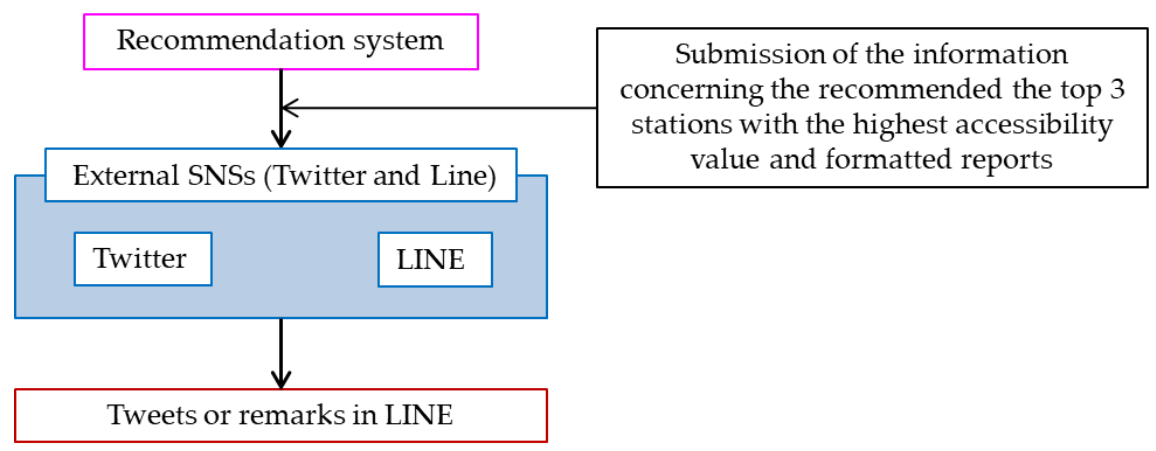

Figure 8. Conceptual diagram related to the process of the sharing system of the information concerning the meet-up station linked with external SNSs.

\subsection{System Interface}

The system has two types of interfaces: the users' screen for PCs and mobile devices (Figure 9) and the administrators' screen for PCs. The administrators can see the list of the "member number", "ID", "Age", "Gender", and "email address (optional)" of all users. Additionally, due to the simplification of user management using graphic user interface (GUI), procedures, such as the deletion of unauthorized users, can be done without depending on the Information Technology (IT) literacy of the administrators. 


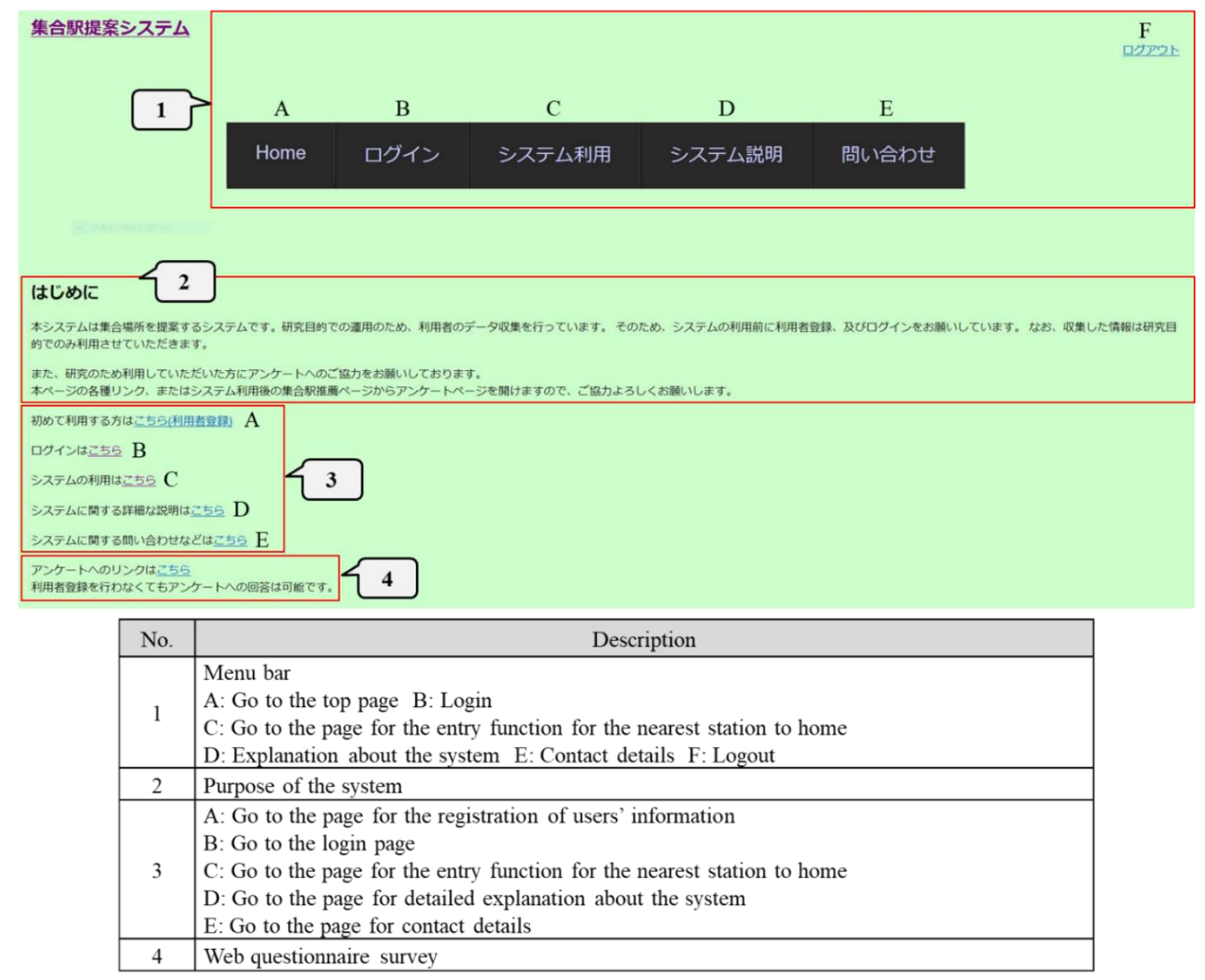

Figure 9. Users' screen for PCs and mobile devices and explanation of each function.

\section{Operation}

\subsection{Overview of the Operation Target Area and User Assumption}

\subsubsection{Selection of the Operation Target Area}

Nippon Budokan (Chiyoda Ward, Tokyo), which is the destination for many events, was decided upon as the operation target area for the system in the present study, and Kudanshita station was determined to be the nearest station to the destination. All railway lines (128 lines) within the Tokyo metropolitan area (Tokyo, Kanagawa, Saitama, and Chiba) were set as calculation targets for the accessibility value. Based on this setting, the railway lines belonging to the suggested meet-up stations are the three lines that stop at the Kudanshita station: the Toei Shinjuku Line, the Tokyo Metro Tozai Line, and the Tokyo Metro Hanzomon Line. Accordingly, it is possible to obtain accurate recommendations for the meet-up stations for various groups. Because most people have visited Nippon Budokan more than once and it is the most popular event venue in the Tokyo Metropolitan Area, it was selected as the operation target area for the system in the present study.

\subsubsection{User Assumption}

The users of the system are assumed to be those attending events. The system will recommend meet-up stations for such users before and after the event, encouraging them to gather in places away from the event venue. 


\subsection{Operation}

\subsubsection{Operation Overview}

The operation of the system was conducted for 5 weeks with those mainly in the Tokyo metropolitan area. The website of the authors' laboratory, as well as Twitter and Facebook, were used to advertise the operation of the system in the present study. The users had to register when using the system for the first time. This was done by registering an "ID" and a "password". After completing this registration, the users were automatically directed to the top page, enabling them to use the various functions available within the system. From the top page moving on to the page for the detailed explanation about the system as shown in Figure 9, the users could learn more about the equations used to calculate the accessibility values saved in the database, as well as the background operations of the system.

\subsubsection{Management of Submitted Information by Administrators during the Operation}

Every user's submitted information is accumulated as data in the database of the system. The administrators manage the users and check the submitted information using a list screen designed especially for the purpose. However, the users can freely edit their submitted information and select railway lines and stations. Due to these features, there is no need for the administrators to search to see whether or not inappropriate submissions of information have been made within the system; therefore, their burden can be lessened.

\subsubsection{Operation Results}

Table 2 indicates an overview of the system users. There is a total of 59 users, with 45 male users and 14 female users. Regarding the age of the users, there are many users in their $20 \mathrm{~s}$ of both males and females, making up around $73 \%$ of the total. A total of $8 \%$ were in their $30 \mathrm{~s}, 7 \%$ in their $40 \mathrm{~s}$ and $50 \mathrm{~s}$, and $5 \%$ in their teens. In order to increase a wider range of users, as future study projects, the system will be improved based upon the evaluation results introduced in the next section.

Table 2. Overviews of system users and web questionnaire survey respondents.

\begin{tabular}{ccccccc}
\hline Age Groups of Users & $\mathbf{1 0 - 1 9}$ & $\mathbf{2 0 - 2 9}$ & $\mathbf{3 0 - 3 9}$ & $\mathbf{4 0 - 4 9}$ & $\mathbf{5 0 - 5 9}$ & Total \\
\hline Number of users & 3 & 43 & 5 & 4 & 4 & 59 \\
Number of web questionnaire & 1 & 32 & 0 & 3 & 3 & 30 \\
survey respondents & 33.3 & 74.4 & 0.0 & 75.5 & 75.5 & 66.1 \\
Valid response rate (\%) & 33.3 &
\end{tabular}

\section{Evaluation}

After the end of the operation, a web questionnaire survey and access analysis of the users' log data were conducted in order to evaluate the system developed in the present study. It is important to consider that the users were biased by age when the system is evaluated in this section. However, this result reflects that younger people tend to frequently use various web services in their daily lives.

\subsection{Evaluation Based on Web Questionnaire Survey}

\subsubsection{Overview of the Web Questionnaire Survey}

Along with the aim of the present study, a web questionnaire survey was implemented in order to conduct (1) an evaluation concerning the use of the system and (2) an evaluation concerning the functions of the system. The web questionnaire survey was conducted for 1 week after the start of the operation. Table 2 also indicates an overview of the web questionnaire survey respondents. As shown 
in Table 2, 30 out of 59 users submitted their web questionnaire survey, and the valid response rate was approximately $66 \%$.

\subsubsection{Evaluation Concerning the Use of the System}

(1) Evaluation Concerning the Compatibility with the Purpose of Using the System as well as User Tendencies

Regarding the viewing frequency of the website, $97 \%$ answered "everyday". On the other hand, for the frequency of meeting up with people, $8 \%$ answered "everyday", $21 \%$ answered "a few times a week", $46 \%$ answered "a few times a month", and 15\% answered "almost never". For meet-up locations, $23 \%$ answered "at the destination", $46 \%$ answered "mostly at the destination", $21 \%$ answered "mostly at locations other than the destination", and 10\% answered "locations other than the destination". From this result, it is evident that most people tend to meet at destinations, and they try to gather around the event venue before and after the event. Therefore, by properly recommending meet-up stations to the users using the web system in the present study and encouraging them to meet up there, it is possible to reduce congestion in areas surrounding event venues.

\section{(2) Evaluation on the Use of the System}

For the devices (multiple answers allowed) on which the system was used, $46 \%$ answered PC, $59 \%$ answered smartphone, and 5\% answered tablet device. Therefore, the system is mainly used on PCs and smartphones, and more people use it on their smartphones. These results are appropriate for the purpose of using the system, which is to have the users use it any time before meeting up with their friends.

\subsubsection{Evaluation Concerning the Functions of the System}

Figure 10 describes the evaluation results for each function, as well as for the entire system.

\section{(1) Evaluation of the Entry Function for the Nearest Station to Home}

Regarding the easiness of entry for the nearest station to home, 77\% answered "I think so" or "I somewhat think so", while $23 \%$ answered "I don't think so" or "I don't think so at all". The first reason for the negative reviews is that the system did not have an interface optimized for smartphones, though $59 \%$ used the system from their smartphones, as indicated in Section 7.1.2. The second reason is that there are many railway lines in the Tokyo metropolitan area, and it was difficult for the users to select the nearest station to home, due to the system design in which the users must first select a railway line and then a station, as mentioned in Section 3.4.

\section{(2) Evaluation of the Recommendation Function for the Meet-Up Stations}

Regarding the suitability of the calculation basis for the accessibility values, it was given an extremely high rating, with 95\% answering "I think so" or "I somewhat think so". Therefore, as mentioned in Section 4.2, the suitability of the bases for calculation, which are the travel time and number of transfers to the destination, as well as the average number of passengers getting on and off at the arrival station per day, were made evident. Regarding the suitability of the suggested meet-ups stations, $46 \%$ answered "I think so" and $44 \%$ answered "I somewhat think so", while $10 \%$ answered "I don't think so". From these results, it is evident that some of the users were not satisfied, though the recommendation results were suitable for the majority of the users. Regarding the suitability of the number of meet-up stations recommended (three stations), as 77\% answered "I think so" and $13 \%$ answered "I somewhat think so", it is clear that it was extremely well-received by the users. From these results, the users' satisfaction can be increased by improving the calculation method for the accessibility values and the handling of such values in the system, without changing the calculation basis for the accessibility values and the number of meet-up stations recommended. 
Regarding the convenience of the links with both Google Maps and external SNSs (Twitter and LINE), 92\% answered "I think so" or "I somewhat think so", while $8 \%$ answered "I don't think" or "I don't think so at all". The latter was especially highly rated with $77 \%$ answered "I think so". This shows that the users highly rated how the system was designed for the purpose of improving convenience. Additionally, the sharing function where users can share the meet-up stations with their group using external SNSs linked with the system was especially highly rated.

(3) Evaluation Related to the Entire System

Regarding the suitability of the entire interface, $82 \%$ answered "I think so" or "I somewhat think so", while $18 \%$ answered "I don't think" or "I don't think so at all". One reason for the negative reviews was that the interface of the system was not optimized for smartphones as mentioned before.

Regarding the usefulness of the system when meeting up in groups, $90 \%$ answered "I think so" or "I somewhat think so", while $10 \%$ answered "I don't think". Therefore, because the serviceability of the system is high when meeting up in groups, by making the improvements mentioned later in Section 7.3, it can be anticipated that the users will be able to make more use of each function of the system.

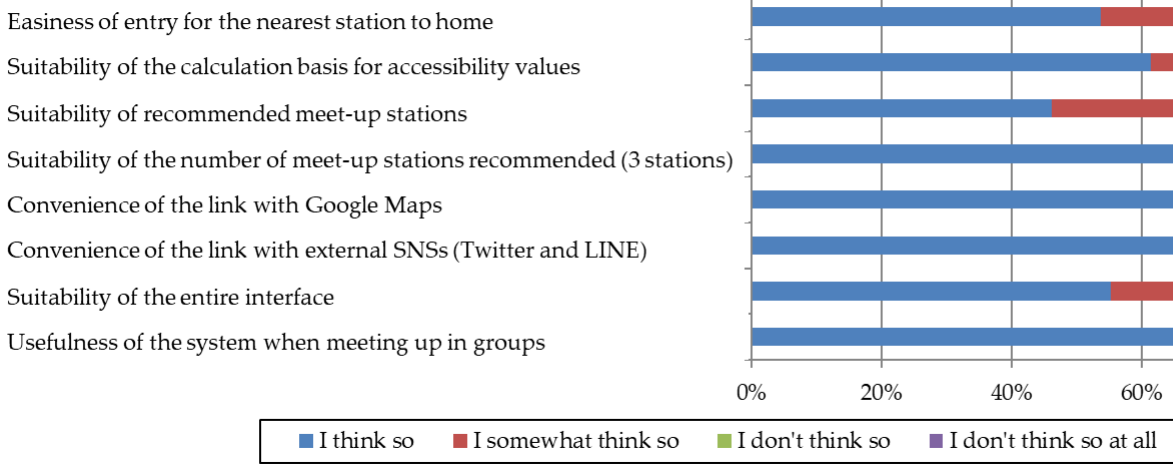

Figure 10. Evaluation related to each function, as well as for the entire system.

\subsection{Evaluation Based on Access Analysis}

In the present study, an access analysis was conducted using the users' log data during the operation period. This analysis was conducted using Google Analytics, which is a web access analysis service provided by Google. A PHP program with the analysis code made using Google Analytics was created, and for the target websites for the access analysis, the access log was obtained by scanning the PHP program made for the access analysis of the program in each page within that website.

Table 3 shows the access methods to the system. With information terminals used as access methods, $40 \%$ were PCs and $60 \%$ were mobile devices, indicating that there was more access from the latter rather than the former. This is because many people have begun to use smartphones as a simple and convenient way to obtain information in recent years. The system design was effective in that it was made to be used regardless of the type of device in order to eliminate the difference in information that can be obtained depending on the device. However, as mentioned in Section 7.1.3, as the system did not have an interface optimized for smartphones; thus, despite there being more access from smartphones than PCs, the users found it somewhat difficult to use the system from their smartphones.

Table 4 shows the number of visits according to page (top 10). As it is made evident in Table 4 , there were 59 users using the system, and the number of visits to the page for the recommendation function for the meet-up stations was 119, which means each user used this function twice. This may be because the users attended each event with a different group and used the system with various groups. Additionally, the number of visits to the page for the explanation about the system was 121, 
suggesting that the users fully understood the system while using it. Therefore, it can be said that the users understood the system when evaluating each function in the questionnaire survey.

Table 3. Access Methods.

\begin{tabular}{ccc}
\hline Access Method & Number of Sessions & Percentage (\%) \\
\hline PC & 119 & 40.2 \\
Smartphone & 155 & 55.4 \\
Tablet & 13 & 4.4 \\
\hline
\end{tabular}

Table 4. Number of visits according to page (top 10).

\begin{tabular}{clc}
\hline Rank & \multicolumn{1}{c}{ Page Name } & Number of Visits \\
\hline 1 & Top page & 471 \\
2 & Login page & 241 \\
3 & Page for the entry function for the nearest station to home & 166 \\
4 & Page for the explanation about the system & 121 \\
5 & Page for the recommendation function for the meet-up stations & 119 \\
6 & Page for the registration of users' information & 90 \\
\hline
\end{tabular}

\subsection{Extraction of Improvement Measures}

The issues concerning the system were extracted based on the results of the web questionnaire survey, as well as the access analysis of the users' log data and are summarized below.

(1) Interface

The system developed in the present study displayed the screen for PCs on mobile devices including smartphones and tablets. Because of this, users found it difficult to use the system, particularly from their smartphones, especially when they selected the nearest stations to their homes. Therefore, in addition to implementing an interface for mobile devices, it is necessary to improve the page for the entry function for the nearest station to home.

\section{(2) Recommendation System}

The system recommends meet-up stations by referring only to the accessibility value from the nearest station to home to the suggested meet-up stations and does not consider the time, distance of the event venue, or the nearest station to the destination as the meet-up station. Therefore, it is necessary to take this into consideration and enhance the recommendation system.

\section{(3) Destination Settings}

Because the system operated with Nippon Budokan as the only destination, the system's serviceability would be improved if the number of event venues as destinations increased.

\section{Conclusions}

In the present study, after designing the system (Section 3), the accessibility was defined, the database was created (Section 4), and the development (Section 5) and the operation (Section 6), as well as the evaluation and extraction of improvement measures (Section 7), were conducted. The present study can be summarized into the following three points.

(1) As shown in Sections 3 and 4, in order to recommend meet-up stations for groups during events, combining an accessibility database, as well as a recommendation system, the present study designed and developed a system linked with Google Maps and SNSs. Additionally, by defining 
accessibility as the closeness between two arbitrary stations reflecting current usage situations, it was made possible to digitalize the accessibility between the nearest station to home and the suggested meet-up stations. The system was operated and evaluated with Nippon Budokan set as the destination event venue, the Kudanshita station as the nearest station to the destination, and all the railway lines within the Tokyo metropolitan area as the calculation target lines for the accessibility value.

(2) As described in Sections 5-7, the system was operated over a period of 5 weeks with people mainly in the Tokyo metropolitan area, and the total number of the users was 59. Then, a questionnaire survey was conducted with the users as the target. From the results of the questionnaire survey, it was made evident that the system is useful for groups when meeting up, and by continuously operating, it can be anticipated that the users will make more use of each function in the system. The entry function for the nearest station to home, as well as the recommendation function for the meet-up stations, which are the original functions of the system, received generally good reviews. Furthermore, by implementing an interface optimized especially for smartphones, the system can be made even more convenient for the users.

(3) As described in Sections 6 and 7, from the results of the access log analysis, it was made evident that the system was used regardless of the type of device just as the system was designed and that the system was used in harmony with the aim of the present study, which is to recommend meet-up stations for groups. However, because the system is accessed more often by smartphones than PCs, it is necessary to implement an interface for smartphones, as previously mentioned.

As future study projects, the improvement of the system based on the results in Section 7.3, as well as the enhancement of the significance of using the system by gaining more results in other urban sightseeing areas can be developed. Additionally, it is desirable to develop a unique mobile application based on the system in the present study.

Author Contributions: S.A. design, develop and operate the recommendation system regarding meeting places for groups in the present study. He also initially drafted the paper. K.Y. carried out background work, and evaluates the system. All authors contributed to write up and review, and approved the paper manuscript.

Acknowledgments: In the operation of the recommendation system regarding meeting places for groups and the web questionnaires survey of the present study, enormous cooperation was received from those mainly in the Tokyo Metropolitan Area. We would like to take this opportunity to gratefully acknowledge them.

Conflicts of Interest: The authors declare no conflict of interest.

\section{References}

1. Ishizuka, J.; Suzuki, Y.; Kawagoe, K. Method for searching for similarities in data on movement paths, designed to support sightseeing in Kyoto. The special interest group technical reports of information processing Society of Japan, CVIM. Comput. Vis. Image Underst. 2007, 1, 17-23.

2. Kurashima, T.; Iwata, T.; Irie, G.; Fujimura, K. Travel route recommendation using geotags on photo sharing service. In Proceedings of the 19th ACM International Conference on Information and Knowledge Management, Toronto, ON, Canada, 26-30 October 2010; pp. 55-60.

3. Kurata, Y. Introducing a Hot-Start Mechanism to a Web-based Tour Planner CT-Planner and Increasing its Coverage Areas. In Proceedings of the Geographic Information Systems Association of Japan, Hiroshima, Japan, 13-14 October 2012; p. 4.

4. Sasaki, J.; Uetake, T.; Horikawa, M.; Sugawara, M. Development of personal sightseeing support system during long-term stay. In Proceedings of the 75th National Convention of IPSJ, Miyagi, Japan, 6-8 March 2013; pp. 727-728.

5. Fujitsuka, T.; Harada, T.; Sato, T.; Takadama, K. Recommendation system for sightseeing plan using pattern mining to evaluate time series action. In Proceedings of the Annual Conference on Society of Instrument and Control Engineering 2014, Hangzhou, China, 28-30 July 2015; pp. 802-807. 
6. Ueda, T.; Ooka, Y.; Kumano, K.; Hiroyuki, T.; Toshihiro, H.; Masato, Y. Sightseeing Support System to Support Generation/Sharing of Sightseeing Information. In The Special Interest Group Technical Reports of IPSJ: Information System and Social environment (IS); Information Processing Society of Japan: Tokyo, Japan, 2015; pp. 1-7.

7. Fujita, S.; Yamamoto, K. Development of dynamic real-time navigation system. Int. J. Adv. Comput. Sci. Appl. 2016, 7, 116-130. [CrossRef]

8. Mizushima, T.; Hirota, J.; Kazuya, O.K.; Aoyama, K. Service Data Model in Design Support System for Sightseeing Tours. In Serviceology for Smart Service System; Sawatani, Y., Spohrer, J., Kwan, S., Takenaka, T., Eds.; Springer: Tokyo, Japan, 2017; pp. 55-64.

9. Yamamoto, K. Navigation System for Foreign Tourists in Japan. J. Environ. Sci. Eng. 2018, 10B, 521-541.

10. Van Canneyt, S.; Schockaert, S.; Van Laere, O.; Dhoedt, B. Time-dependent recommendation of tourist attractions using Flickr. In Proceedings of the 23rd Benelux Conference on Artificial Intelligence, Ghent, Belgium, 3-4 November 2011; pp. 255-262.

11. Batet, M.; Moreno, A.; Sánchez, D.; Isern, D.; Valls, A. Turist@: Agent-based personalised recommendation of tourist activities. Expert Sys. Appl. 2012, 39, 7319-7329. [CrossRef]

12. Uehara, H.; Shimada, K.; Endo, T. Sightseeing Location Recommendation using Tourism Information on the Web. In Technical Report of the Institute of Electronics, Information and Communication Engineers, NLC, "Natural language Understanding and Models of Communication"; Institute of Electronics, Information and Communication Engineers: Tokyo, Japan, 2012; Volume 112, pp. 13-18.

13. Shaw, B.; Shea, J.; Sinha, S.; Hogue, A. learning to rank for spatiotemporal search. In Proceedings of the 6th ACM International Conference on Web Search and Data Mining, Rome, Italy, 4-8 February 2012; pp. 717-726.

14. Ikeda, T.; Yamamoto, K. Development of social recommendation GIS tourist spots. Int. Adv. Comput. Sci. Appl. 2014, 5, 8-21. [CrossRef]

15. Okuzono, M.; Muta, M.; Hirano, H.; Masuko, S.; Hoshino, J. Recommendation System of Sightseeing Area for Groups. the Special Interest Group Technical reports of IPSJ: Human Computer Interaction (HCI); Information Processing Society of Japan: Tokyo, Japan, 2015; Volume 19, pp. 1-8.

16. Zhou, J.; Yamamoto, K. Development of the system to support tourists' excursion behavior using augmented reality. Int. J. Adv. Comput. Sci. Appl. 2016, 7, 97-209. [CrossRef]

17. Mizutani, Y.; Yamamoto, K. A sightseeing spot recommendation system that takes into account the change in circumstances of users. Int. J. Geo-Inf. 2017, 6, 303. [CrossRef]

18. Xu, B.; Ding, Z.; Chen, H. Recommending locations based on users' periodic behaviors. Mob. Inf. Sys. 2017, 2017. [CrossRef]

19. Abe, S.; Miki, D.; Yamamoto, K. A tourism information system with language-barrier-free interfaces for foreign visitors. In Proceedings of the International Conference and Management (BEM) and International Conference on Marketing and Tourism (MAT), Tokyo, Japan, 5-6 August 2017; pp. 58-66.

20. Jang, T.; Ryoji Matsunaka, A.; Daisuke Kirobayashi, D. A study on the accessibility index for evaluating the railway service level. Infrastruct. Plan. Rev. 2000, 17, 75-82. [CrossRef]

21. Atsumaru-now. Available online: http:/ / atsumaru-now.com/ (accessed on 14 April 2017).

22. NAVITAME. Available online: https://www.navitime.co.jp/ (accessed on 14 April 2017).

23. Yahoo!JAPAN. Available online: https://transit.yahoo.co.jp/ (accessed on 14 April 2017).

24. Ministry of Land, Infrastructure, Transport and Tourism. Digital National Land Information. Available online: http:/ / nlftp.mlit.go.jp/ksj/ (accessed on 14 April 2017).

25. Station Data. Jp. Station Data. Available online: http://www.ekidata.jp/ (accessed on 14 April 2017).

(C) 2018 by the authors. Licensee MDPI, Basel, Switzerland. This article is an open access article distributed under the terms and conditions of the Creative Commons Attribution (CC BY) license (http://creativecommons.org/licenses/by/4.0/). 